\title{
Lo no revelado. Una aproximación al dibujo de John Hejduk a través del proyecto Victims
}

The unrevealed. An approximation to John Hejduk's drawing by means of Victims project

Louis Sebastián Sequeda Toro

Universidad Nacional de Colombia, Colombia lssequedat@unal.edu.co

https://orcid.org/0000-0002-9431-3846 


\title{
Resumen
}

Al observar la obra de John Hejduk, es posible notar que esta no entra en el canon de la producción arquitectónica tradicional. Sus libros parecen estar cubiertos por un velo que aleja la interpretación directa y, al mismo tiempo, cautiva e intriga profundamente al espectador que se encuentra con ellos. A través del análisis de los elementos que componen Victims, una de sus mascaradas paradigmáticas, este artículo sugiere que Hejduk fragmenta sus obras de tal forma que deja solo lo fundamental de cada parte, dando las piezas mínimas de un gran rompecabezas de múltiples soluciones, el cual deberá ser resuelto por los espectadores que se sumergen en su universo. Su indagación por la esencia lo llevaron a encontrar el medio y la información justa para cada fragmento, lo necesario para re-presentar aquello que es realmente importante de la condición humana. Un recorrido por sus dibujos, textos y referencias permite evidenciar su forma única de dibujar donde deja de lado información complementaria que daría una guía clara de la narración que está creando, no entrega todo al observador, por el contrario, lo que busca es delegarle la tarea de develar las ideas y de armar una historia propia. Gracias a un dialogo entre varios escritos del arquitecto y Victims, es posible clarificar las motivaciones de Hejduk para materializar sus ideas arquitectónicas de una forma tan particular, en la cual trazos y letras se entrelazan formando una sola obra de carácter profundamente personal.

Palabras clave: John Hejduk; Victims; dibujo arquitectónico; representación; mascaradas.

\begin{abstract}
Observing John Hejduk's work, it is possible to note that it does not fit in the architectural production canon. His books seem to be covered by a veil which takes away the obvious interpretation and, at the same time, deeply captives and intrigues the observer who looks at them. Through an analysis of the elements from one of his paradigmatic masques, Victims, the journal suggest that Hejduk fragments his work to reach the fundamental of each part, to give the minimal pieces from a puzzle with undefined solutions which must be solved by the viewer who decide to immerse in his universe. His pursuit for the essence leads him to find the proper medium and information for each fragment, the necessary to re-present what is important in the human condition. Explore his drawings, texts and references allows to evidence his unique way of drawing. He leaves aside complementary information that would enable a clear guide to the narrative he is creating, he does not give everything to the observer, conversely, what he seeks is to delegate the task of unrevealing the ideas to create individual stories. Comparing architect's writings and Victims, it is possible to clarify Hejduk's motivations to materialize his architectural ideas in such a unique form, in which lines and letters intertwine to form a deeply personal work.
\end{abstract}

\section{Key words: John Hejduk; Victims; architectural drawing; representation; masques.}

\section{Para citar este artículo / To cite this article:}

SEQUEDA, L. S. Lo no revelado. Una aproximación al dibujo de John Hejduk a través del proyecto Victims.. En: [i2] Investigación e Innovación en Arquitectura y Territorio [en línea]. 2021, Vol. 9, Núm. 2, pp. 27-50. ISSN: 2341-0515. https://doi.org/10.14198/I2.17412 


\section{El arquitecto}

Encarar la obra de John Hejduk puede ser una de las experiencias más intrigantes y desafiantes que hay. Su trabajo, profundamente personal y plagado de referencias que van desde la mitología griega hasta los grafitis de Nueva York, nunca deja indiferente a quien lo ve, por el contrario, le genera desconcierto, extrañez y múltiples preguntas. El universo que el arquitecto neoyorquino ha creado, como todo aquello que ama la máscara, invita a quien se encuentra con él a descubrirlo y redescubrirlo continuamente. Es un acto maravilloso que, en lugar de producir certezas, se expande con cada nueva mirada.

Para Hejduk, sugiere Gersten (2019), el sustento de la arquitectura está “en el potencial creativo del individuo como un acto social, en la capacidad de la imaginación individual para producir espacios comunes" ${ }^{1}$. Su obra y pedagogía son un fiel reflejo de esta idea. A lo largo de su carrera, desde el Nine Square Problem (1954-1963), pasando por los proyectos de las Diamond Houses (1963-1967) y llegando a las Masques (1979-2000), Hejduk fue creando un trabajo donde las indagaciones personales son aquellas que generan el impulso creativo. Donde el artista debe buscar aquello que lo motiva, interesa o preocupa, para lograr plasmarlo a través del arte. De esta forma, al hablar sobre su papel como docente, comenta: “... Más bien trato de sacarlos de sí mismos. En otras palabras, sacar lo que llevan en su interior $y$, simplemente, tocar cierto punto clave que les ayude a desarrollar su idea" (Shapiro, 2010, p. 78).

Sus búsquedas lo llevaron a idear las mascaradas de su tiempo ${ }^{2}$. Una forma de trabajo en la cual, usando el mecanismo ideado en el siglo XVI, las herramientas que normalmente usa la arquitectura son complementadas, y transformadas, por diversos y más expresivos medios artísticos. Es así como poesía, textos, relatos, ideas constructivas, sensaciones, materiales, recuerdos, escenarios y dibujos se entrelazan en su obra de tal manera que esta "parece dejar de buscar el objetivo de la materialización en edificios, para adquirir un carácter narrativo con el fin de transmitir un mensaje” (Bascones, 2017, p. 174).

Las masques ${ }^{3}$ que propone Hejduk están divididas en tres trilogías, cada una de ellas correspondiente a un espacio geográfico determinado: Venecia, Berlín y Rusia. Lugares que son seleccionados por un elemento común, un tipo de aura que los vincula más allá de sus características físicas, su carga mnemónica. A lo largo de estos trabajos, las capas se han ido superponiendo en el lugar a través de la historia, modifican y caracterizan de manera contundente el trabajo que el arquitecto realizó.

\footnotetext{
${ }^{1}$ Traducción propia: “... a vision grounded in individual creativity as a profound social act, in the capaci-ty of the personal imagination to construct shared spaces."

2 En las anatociones descriptivas de Masque, la estructura número 15 de Berlin Masque, Hejduk expresa: “... it would appear that we of our time must create masques (programs ???) for our times” (Hejduk, 1985, p. 152).

${ }^{3}$ Mascaradas, en castellano, es un tipo de creación teatral que tiene su apogeo en los siglos XVI y XVII. Sus principales representantes son Iñigo Jones y Ben Jonson. Tanto Bragdon (2010) como Bascones (2017), desarrollan capítulos referentes al tema.
} 


\section{La Masque}

Victims es concebido como el segundo trabajo de la trilogía de Berlín, después de Berlin Masque (1981) y antes de Berlin Night (1989). En esta obra, al ser el punto intermedio de su deriva, es posible evidenciar las posturas y estrategias que ha ido desarrollando en trabajos previos y, al mismo tiempo, la marcada influencia que tendrá en los futuros. Es la propuesta en la que Hejduk "alcanza un nivel paradigmático en la sistematización de su método y en el diálogo con la memoria” (Bascones, 2017, p 183).

El concurso del parque memorial del Prinz-Albert-Palais, propuesto por la IBA en $1984^{4}$ , fue la razón por la cual se originó el proyecto. Los convocantes buscaban la intervención y reparación de la manzana que albergó el Palacio y su jardín, y la sede de la Gestapo (Fig. 1). Continuo al muro de Berlín y cerca a la puerta de Brandemburgo, el complejo contenía cámaras de tortura, aspecto que Hejduk resalta. Debido a su uso y localización, fue un punto clave del régimen nazi en la capital alemana, un lugar donde fueron pensados y llevados a cabo terribles actos contra la humanidad. Por esta razón, teniendo presente la importancia de preservar la memoria, las bases del concurso proponen que:

La historia de la dictadura nazi debe, por lo tanto, permanecer presente dentro de la historia de sus víctimas por medio de la arquitectura y el arte, sin separarse de la vida de la ciudad en términos de contenido y espacio; por el contrario, a través del lugar debe convertirse en una parte inseparable de la vida. (IBA, 1987, p. 4$)^{5}$

Para 1983, año donde el proyecto fue llevado a cabo, el solar tenía dos edificaciones en pie: el Martin-Gropius-Bau, actualmente un museo de arte, y el Haus der Deutschen Geschichte (EuropaHaus), el cual continúa cumpliendo una función ministerial. En este espacio, Hejduk propone un proyecto encerrado en sí mismo, donde solo por medio de una pasarela arbolada busca la relación con los edificios adyacentes y la ciudad. Una respuesta que refuerza la condición de aislamiento, de enclave independiente. Sin embargo, no niega su entorno, sino provee una visión distinta de la misma realidad. Es un sitio contenido donde, a través de un lenguaje diferente y personal, pueden ser contadas otro tipo de historias, aquellas que hacen verdaderamente falta. En último término, es un teatro que tiene como escenario el suelo de Berlín (Fig. 2).

Hejduk utiliza cuatro elementos para crear este teatro, su mascarada. Primero: el doble muro de setos perimetral, dentro de los cuales circula un tranvía. Es el delimitador del teatro, restringe la escena a un lugar específico. Segundo: la retícula de árboles de hoja perenne. Configura el telón de fondo sobre el cual serán contadas las historias. Tercero: las 67 estructuras (objetos/sujetos) que cumplen el programa del parque. Son los personajes de la obra, aquellos que interactuarán entre sí y con la audiencia. Cuarto: el

${ }^{4}$ IBA: Internationale BauAustellung. Fue un programa dedicado a la creación de nuevos espacios y edi-ficios para la ciudad de Berlín. Por medio de diferentes proyectos, arquitectónicos y urbanos, buscaba intervenir los lugares de la ciudad que estaban degradados desde la Segunda Guerra Mundial.

${ }^{5}$ Traducción propia: "Die Geschichte der nationalsozialistischen Gewaltherrshaft soll mithin Geschichte ihrer Opfer mit Mitteln der Architektur und der Kunst gegenwärtig bleiben, ohne inhaltlich und räumlich vom Leben de Stadt abgespalten zu werden; im Gegenteil, sie soll durch den Ort ein untrennbarer Teil dies Lebens werden." 
tiempo. Es el hilo conector de las narraciones, elemento que cohesiona la propuesta con el lugar y los ciudadanos (Fig. 3).

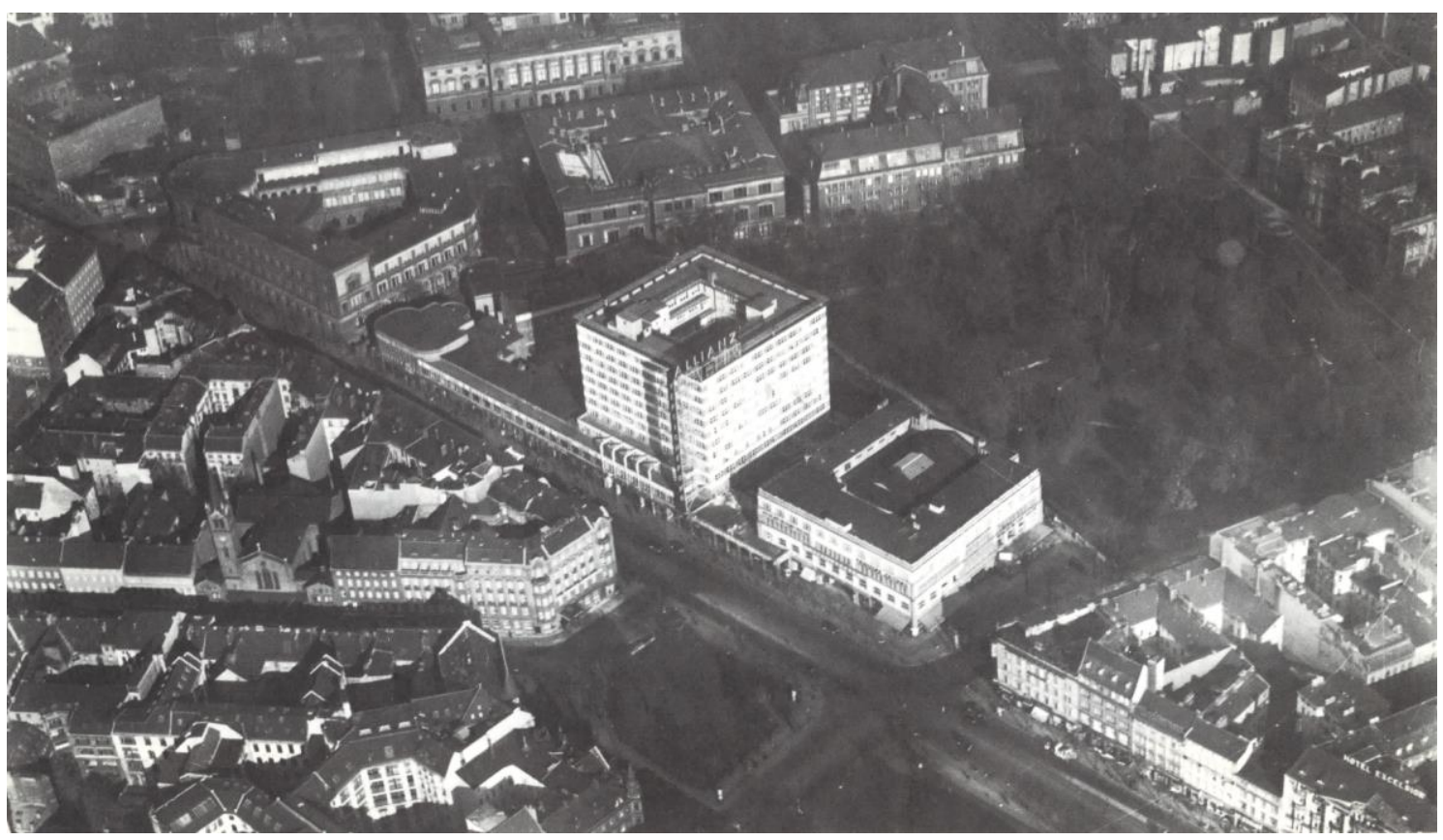

Figura. 1. Vista aérea del lugar. 1935 aproximadamente. Fuente: IBA, 1987: 5.

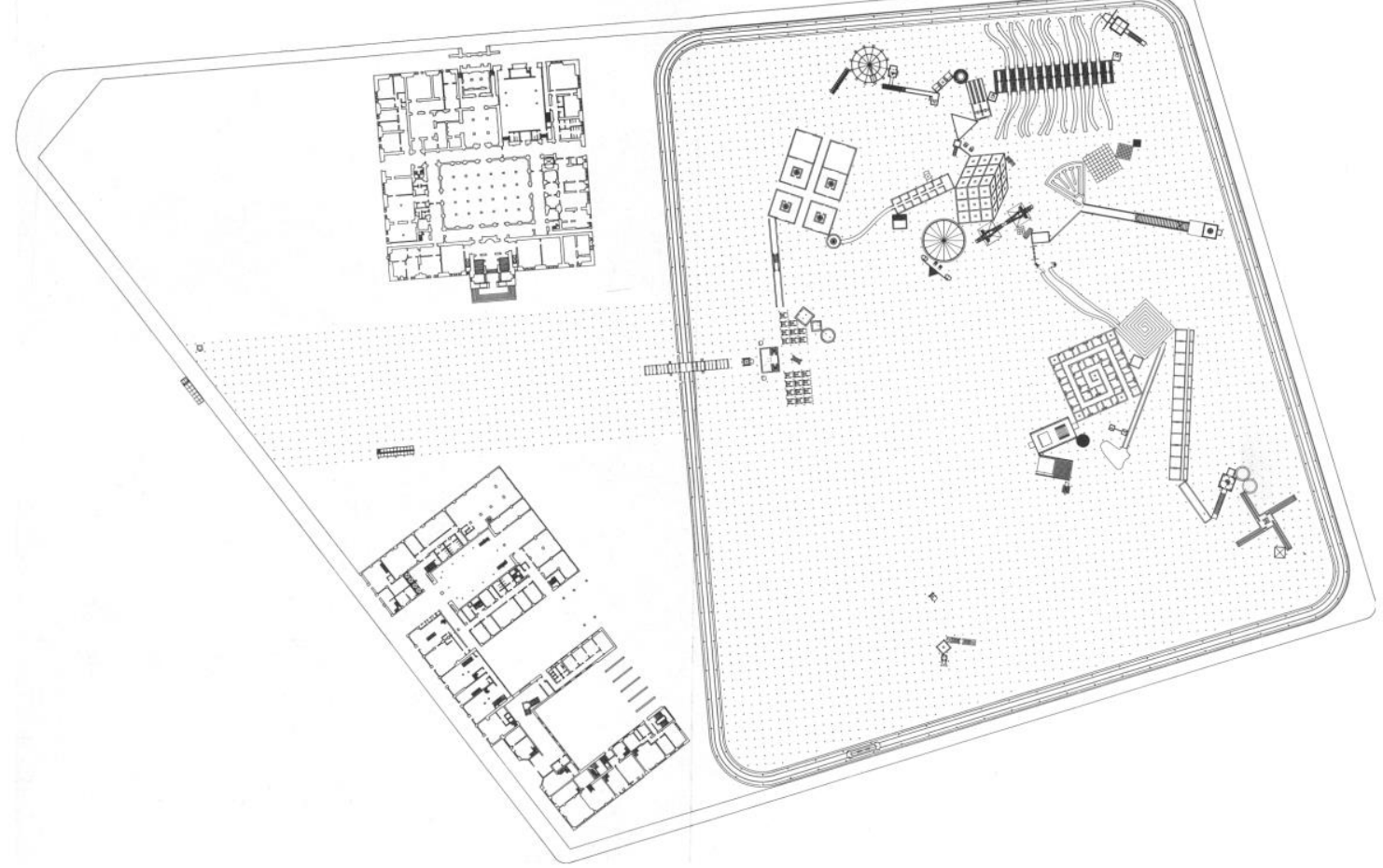

Figura. 2. Plano del nuevo solar. Fuente: Hejduk, 1986 


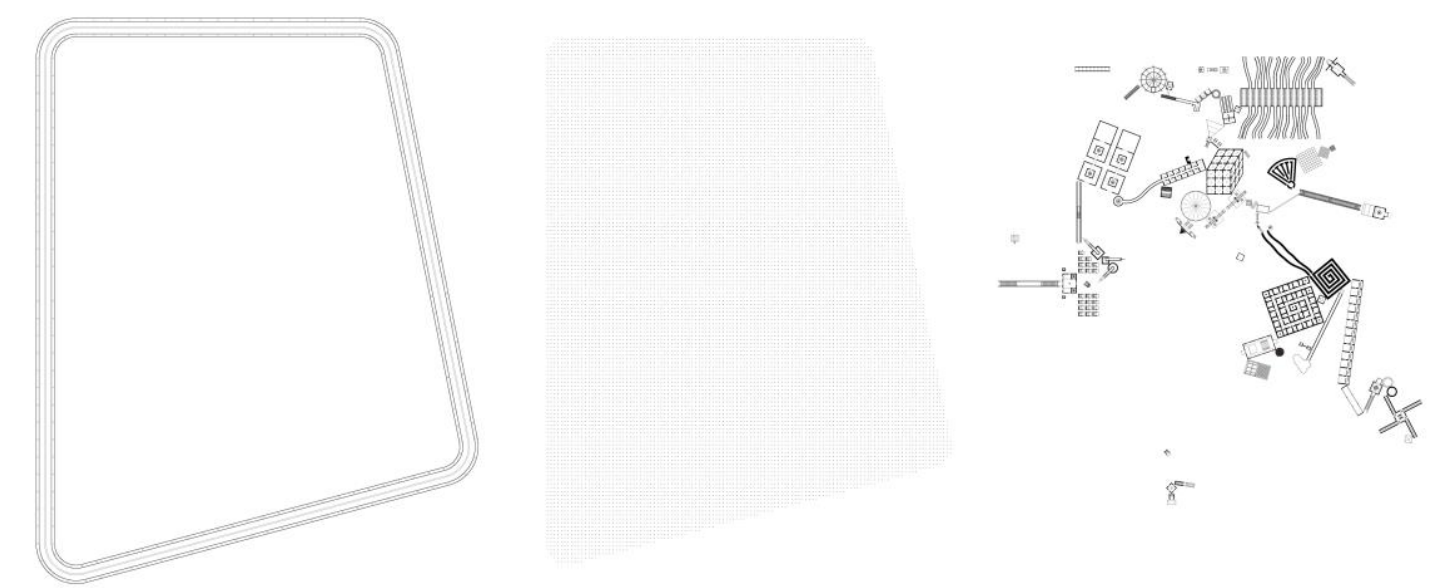

Figura. 3. Elementos articuladores del proyecto. Izq: Setos perimetrales. Centro: Retícula de árboles. Derecha: Objetos/Sujetos. Fuente: Elaboración propia.

Para ejecutar el proyecto plantea una serie de directrices o sugerencias. La propuesta está planteada en dos periodos de 30 años, de una forma creciente, en la cual los ciudadanos y la ciudad crecen a la par que los elementos que componen el proyecto. De esta forma: "Al principio, los árboles son más bajos que las estructuras, después, a través de los años, y en algunos casos, los árboles superan la altura de las estructuras" (Hejduk, 1993, p. 24). Todos los árboles son plantados al mismo tiempo. Las 67 estructuras que conforman el catálogo de Victims, deben relacionarse mediante el contacto tangencial en máximo tres puntos, dando como resultado diversos elementos ubicados de manera extendida sobre el sitio, pero contenidos por la vegetación. Si bien Hejduk da una propuesta de distribución con todas las estructuras, es la ciudadanía quien decide cuales y cuantas serán construidas, además de su disposición final en el solar, dejando el proyecto abierto a un número ilimitado de posiciones y relaciones. Los árboles son cortados para construir las estructuras. Por último, determina la primera fase del proyecto con las acciones a ejecutar que considera mínimas para el funcionamiento del parque.

Hejduk, entendía la importancia de la memoria en este proyecto, su relevancia a la hora de "inventar una construcción del tiempo" (Hejduk, 1993, p. 27). ¿Es el tiempo el vehículo de la memoria o la memoria lo que queda del tiempo? Lo único innegable es la relación directa y reciproca entre los dos.

Desde Berlin Masque (1981), notó que la ciudad de Berlín estaba interesada en hacer lo mismo que él. No era solamente una condición necesaria para la sociedad, sino que la administración trabajaba para incorporar la memoria en los proyectos del presente. De ahí que ese concurso empezara con un extracto de las Ciudades Invisibles de Italo Calvino. El cual habla de la ciudad de Maurilia, un lugar que permite entender "que a veces ciudades diferentes se suceden sobre el mismo suelo y bajo el mismo nombre, que nacen y mueren incomunicables entre sí" (Calvino, 2008, p. 40). Un llamado a evitar que existiesen dos Berlines. Esta realización, fue para él, la oportunidad de indagar acerca de la "naturaleza" del programa y, por medio de las mascaradas, plantear nuevos programas que tuvieran una relación con el espíritu de su tiempo (Hejduk, 1985, p. 135). Y, aunque las bases quedaron establecidas en Berlin Masque, donde hizo "un importante paso hacia 
la definición de su prototipo teatral" (Bascones, 2017, p. 223), su indagación continuó en Victimsy en sus propuestas para Rusia.

La propuesta de Hejduk recibió una mención de honor en el concurso, no obstante, fue criticada por "la arbitrariedad respecto al significado histórico particular" (IBA, 1987, p. $117)^{6}$. Al ver el proyecto ganador ${ }^{7}$, es posible entender el porqué de la crítica. En este, los autores proponían, al igual que Hejduk, una retícula de árboles en todo el solar, pero cubrían la totalidad del piso con láminas de acero, las cuales tenían inscrito en alto relieve la información de miles de documentos que la Gestapo y el régimen nazi expidieron durante su gobierno. De esta forma, visibilizaban el terror oficial por medio de un espacio público abierto y transitable. Los jurados prefirieron una acción literal y fácil de procesar, además de contada desde la oficialidad, a una velada, llena de capas y matices, donde quienes narran lo sucedido son las víctimas. No pudieron interpretar la relación de las estructuras de Hejduk con el lugar, intuyeron, por ende, que lo propuesto era arbitrario.

\section{La obra}

¿Qué hace difícil entender o interpretar la obra de John Hejduk? Seguramente es lo mismo que la hace tan atractiva: su misticismo. La capacidad de transmitir mensajes de manera cifrada, como diría $\mathrm{Moneo}^{8}$, instando a la imaginación y al intelecto a trabajar conjuntamente para descifrar lo que está velado. Sus dibujos y escritos logran narrar un universo único y personal, en el cual la arquitectura desdibuja sus límites formalmente preconcebidos y expande sus horizontes.

Como es conocido, el trabajo de Hejduk estuvo centrado primordialmente en el dibujo y la escritura, la obra construida no logro materializarse en la cantidad que él hubiera querido. Este fue el caso de Victims, aunque pensado para el concurso ya mencionado de la IBA, su impacto llegaría después, cuando fue compartido al público en una exhibición y publicación de la AA en 1986.

Como especifica la contraportada del libro Victims (1986), esta fue la primera publicación de una serie de la AA Publications, dirigida a acortar el vacío existente entre los proyectos ilustrados en libros y las ideas que los inspiraron. Al mismo tiempo, fue construido el monumento/estructura The Collapse of Time (1984), del cual hay registro fílmico. Debido a que los dibujos de Hejduk eran muy vagos para la exhibición y la publicación, Nicholas Boyarsky tuvo la tarea de redibujarlos (AA Files). El entonces estudiante comenta, en una entrevista de la AA, que su forma de dibujar es diferente a la de Hejduk, pero, al momento de hacer los dibujos, imaginó que tenía una sola hoja que

\footnotetext{
${ }^{6}$ Traducción propia: "Kritisch angemerkt jedoch wird die Beliebigkeit in bezug auf die besondere geschichtliche Nedeutung."

${ }^{7}$ Autoría de Jürgen Wenzel y Nikolaus Lang. Debido a diversas circunstancias el proyecto no fue realizado. Finalmente, luego de descartar un proyecto de Peter Zumthor, en el mismo sitio fue construido el centro de documentación/museo llamado La Topografía del Terror, diseñado por Ursula Wilms y Heinz W. Hallmann.

${ }^{8}$ Chiphered Messages, nombre del texto escrito por Rafael Moneo en Bovisa (Hejduk, 1987).
} 
sería cortada después (AA Archives). Una estrategia que simula el estilo de dibujo presente en los diarios de trabajo de Hejduk (Fig. 4).

La publicación contiene la siguiente información:

- $\quad$ Plano del nuevo solar.

- Introducción con instrucciones y sugerencias para el desarrollo del proyecto.

- $\quad$ Pensamientos de un Arquitecto, ideas relevantes para contextualizar la propuesta.

- Narraciones, poemas o etimologías de cada una de las 67 estructuras propuestas.

- Notas para la construcción de un Diario, diversas anotaciones que surgieron mientras hacía el proyecto.

- $\quad$ Planimetrías de las 67 estructuras elaboradas por Boyarsky.

- $\quad$ Bocetos elaborados por Hejduk.

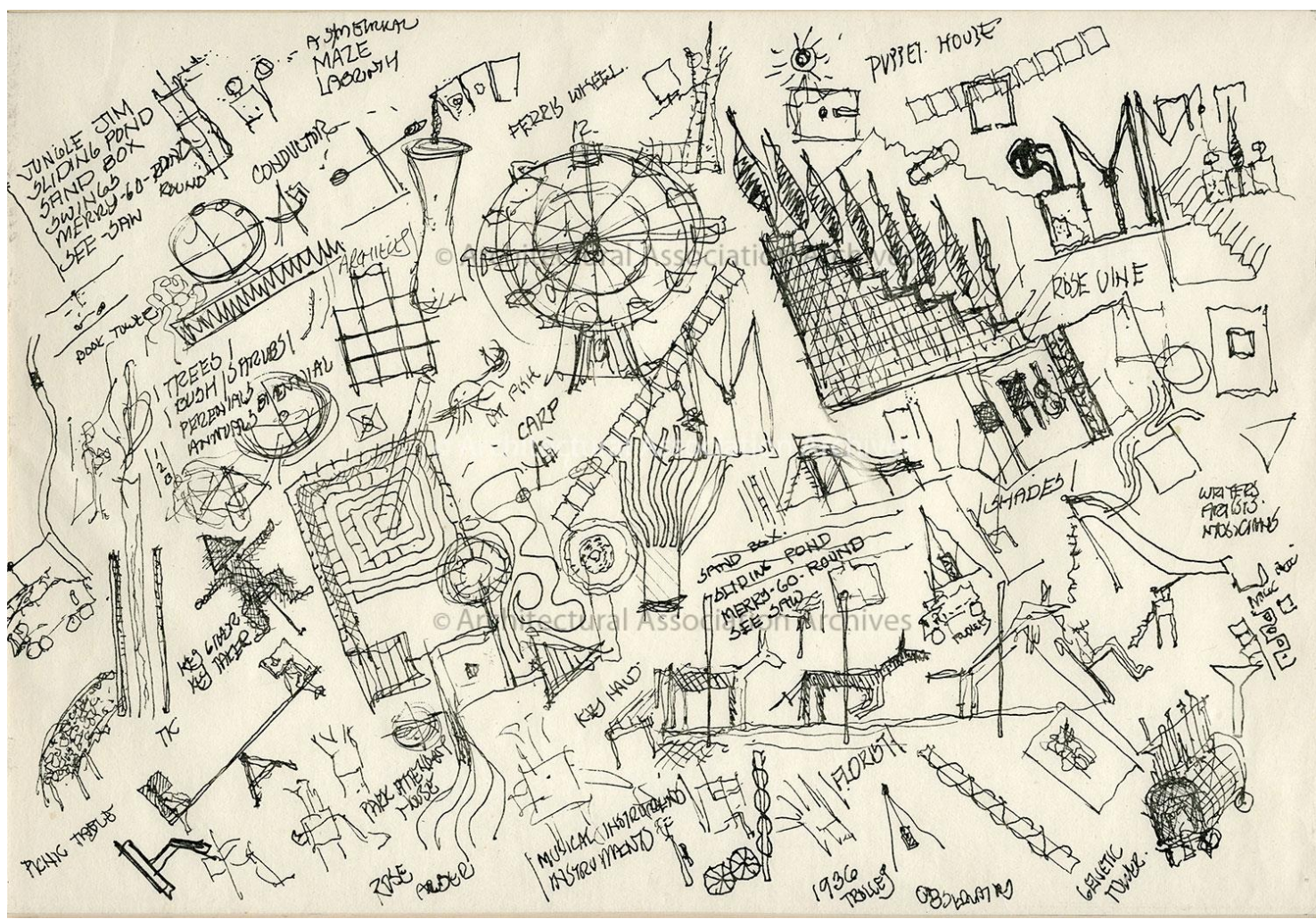

Figura. 4. Boceto de Victims. Fuente: AA Archives.

Los libros publicados con la obra de Hejduk no son las típicas publicaciones de arquitectura donde lo primordial son las planimetrías y las fotografías de los edificios. En sus libros, los textos comparten un papel protagónico junto a las imágenes, no son una contextualización de las últimas. Victims no es la excepción, las narraciones de las estructuras son la mitad de la publicación. 
Cuando un arquitecto está pensando, está pensando arquitectura y su trabajo siempre es arquitectura sin importar la forma que tome. Ningún área es más arquitectónica que otra. Mis libros, por ejemplo, son arquitectura que puedes construir en tu cabeza. (Hejduk, citado en CCA, 1997) ${ }^{9}$

Hejduk entiende la arquitectura como una acción artística creada desde la multidisciplinariedad. Diversas expresiones humanas, sin importar su origen o distancia con la disciplina, pueden ser consideradas obras arquitectónicas. Por tal motivo, para él, tanto el dibujo como la palabra no son representaciones de arquitectura, sino arquitectura. Cuando compone versos o traza líneas, cuando narra historias y llena de color las hojas, está haciendo arquitectura. La condición del hacer arquitectónico no está referida a la representación del espacio, ni como criticaba Evans (1997), al dibujo como obra en sí misma ${ }^{10}$, sino al mundo intangible. Al mundo de las ideas.

Hays (2014, p. 4) explica la postura de Hejduk de la siguiente manera:

Él (Hejduk), por lo tanto, desplaza la pregunta de la representación arquitectónica de lo epistemológico a lo ontológico - es decir, desde el entendimiento de la arquitectura como representación o contenedor de un acto específico del pensamiento a la arquitectura como el acto mismo de idear y pensar ${ }^{11}$.

Todo puede ser arquitectura, en tanto sea consecuencia del pensamiento arquitectónico, mas no su medio u objetivo. La arquitectura no recae, de esta manera, únicamente en los dibujos, las posibilidades de acción se vuelven diversas y, como pasa en la obra de Hejduk, difíciles de encasillar. Los edificios son una manifestación más de la arquitectura, no la única; por lo tanto, las narraciones, los pensamientos, el diario y los bocetos no son anecdóticos, son el proyecto.

El cambio conceptual no sucede en beneficio de un positivismo recalcitrante, donde la razón es entendida como la forma pura y aséptica de interpretar el mundo material. La referencia al pensamiento y al mundo de las ideas, por el contrario, debe ser relacionada con aquello que solo el aura, como ente abstracto, puede albergar. Mente y alma son una. El pensamiento y el espíritu están intrínsecamente relacionados, uno lleva al otro. "La arquitectura también tiene que ver con el sonido, pero no con el sonido pragmático sino con un sonido sobrenatural, un sonido del alma" (Shapiro, 2010, p. 80).

La mente está repleta de memorias y subjetividades. Los impulsos creativos de cada individuo vienen, en cierta medida, de sus emociones vividas. Crear es atravesar los pensamientos, los sentimientos y el tiempo, “diseccionar" la mente para elegir las partes

\footnotetext{
${ }^{9}$ Traducción propia: "When an architect is thinking, he's thinking architecture and his work is always architecture whatever form it appears in. No area is more architectural than any other. My books, for instance, are architecture that you can build in your head."

${ }^{10}$ En el ensayo "Translations from Drawing to Building" Evans reflexiona sobre el papel del dibujo en la arquitectura al evidenciar la distancia existente entre el arquitecto y su obra (edificios). Critica la postura tomada por la mayoría de escuelas de arquitectura, ya que en estas el dibujo es considerado una obra de arte creada directamente por los arquitectos. Los dibujos son la obra del arquitecto, el centro de atención. ${ }^{11}$ Traducción propia: "He thus moves the question of architectural representation from the epistemological to the ontological-that is, from architecture understood as representing or hosting a specific event of thinking to architecture as itself being the event of thought and thinking."
} 
que conformaran el todo. Hejduk narra, de forma poética, la creación arquitectónica en el escrito que hace parte de Mask of Medusa, Cross Over:

Pedazos de memoria yacen por todas partes... expuestos... ¿Nos atrevemos a recogerlos? Esos fragmentos pueden cortar profundamente... tienen una interioridad. ¿Quizás son las acupunturas del alma? ¿Cómo es que las revoluciones adquieren tal celo religioso? Los dibujos también hablan de hospitales... los tubos de drenaje están por todas partes. ¿Están ayudando a mantener viva la abstracción? ¿La abstracción fue herida por proposiciones planas? ¿Es esto una proyección de cómo se vería el campo de batalla de la biosfera luego de la guerra? ¿Estamos viendo los primeros rayos $x$ de la "ciudad de la mente"? Si, nuestra mente-alma debe verse así... momentos de densidad moviéndose hacia un punto de fuga. La periferia grabada en huecos vacíos. Es preocupante... hay trampas por todas partes... terminar flotando perpetuamente. (Hejduk, 1985, p. 94) ${ }^{12}$

Más adelante, en el mismo texto, finaliza escenificando una condición propia del hacer arquitectónico, la aproximación:

Elementos de edificios pasados siempre están en el presente. Son nuestras mentes las que especulan sobre futuras arquitecturas, sabiendo bien que todo es una hélice en el espacio girando en espiral, moviéndose de una oscuridad a otra ${ }^{13}$.

De una incertidumbre a otra, nada está definido y al igual que el pensamiento, la arquitectura es cambiante, llena de posibilidades e interpretaciones. Sobre esta condición también diría: "Un pintor o un escultor pueden ser puristas, un arquitecto no, solo trabajamos con aproximaciones, siempre puede cambiar algo en arquitectura" (Shapiro, 2010, p. 80).

Si para Hejduk la arquitectura es pensamiento, entonces, ¿cómo "materializa" el pensamiento? ¿Cuáles son las formas que este toma? Principalmente son dos: los trazados y las letras. A lo largo de sus trabajos, unos han estado al lado de las otras, componiendo la misma obra desde frentes distintos pero complementarios. Son entendidos, por lo tanto, como "estructuras espirituales/materiales" (Hejduk, citado en Bascones, 2017, p. 345). La tinta forma entes abstractos del mismo valor. Una sucesión de puntos puede traer a la memoria una vocal o un material. En ambos casos, la arquitectura está dialogando con el observador.

Bascones clarifica esta relación al resaltar la cita que Hejduk hace de la Torah. Las letras son, según la tradición hebrea, entes que conectan el plano espiritual con el terrenal. En

12 Traducción propia: "Shards of memory lie everywhere... exposed... dare we pick them up? Those fragments can cut deep... they have an internality. Perhaps they the are the acupunctures to the soul? How is it that revolution take on such a religious zeal? The drawings speak of hospitals too... drainage tubes are everywhere. Are they helping to keep abstraction alive? Was abstraction wounded by blunt propositions? Is it a projection of how the after battle field of the bio-sphere could look? Are we looking at the first X-ray of the "city of the mind"? Yes, our mind-soul must look like that... moments of density moving towards a vanishing point. The periphery recorded in empty gaps. It is worrisome... traps everywhere... to fall into perpetual float."

${ }_{13}$ Traducción propia: Old building elements are always in the present. It is our minds that speculate on architecture futures, knowing full well it is all a helix spiralling in space moving a darkness.” 
ellas no existe la división platónica, ya que "son esencias espirituales cuya forma exterior corresponde con su esencia interna.” (Hejduk, citado en Bascones, 2017, p. 345). La esencia espiritual de las letras y las letras son una sola entidad, logran su plenitud al momento de entrar en contacto. A partir de la complementariedad.

Hejduk busca que el pensamiento, el espíritu, sea uno con la materia. Es así como intenta que, al momento de presenciar el dibujo, el alma puede ser transmita. "Cuando la búsqueda es exitosa, esta puede expresar lo inefable, lo cual es, en última instancia, traducido como espíritu. Imagina un dibujo y una oración tomando forma al mismo tiempo" (Hejduk, citado en CCA, 1997) ${ }^{14}$.

Esta es la razón por la cual Hejduk se refiere a sus estructuras como “objetos/sujetos" ${ }^{15}$, los personajes de sus mascaradas aspiran a tener las cualidades de las letras de la Torah (Fig. 5). A ser íconos o símbolos que puedan transmitir un alma particular cuando un individuo entre en contacto con ellos. De forma similar, en el ensayo que acompaña a Bovisa (Hejduk, 1987), Moneo habla del esfuerzo de Hejduk por unir función y representación en una única construcción, y advierte la similitud de las estructuras con los criptogramas egipcios. En Victims la relación estructura-letra es evidente. En los pensamientos de un Arquitecto, (Hejduk, 1993. p. 27) declara: “Trazar condensando. Inundar (densificación líquida) el emplazamiento con letras perdidas y signaturas desaparecidas. Gelatinizar el olvido.”

\section{Los trazos, las letras y los pensamientos}

En el campo arquitectónico han sido establecidas una serie de convecciones que permiten comprender las distintas partes, características y cualidades de un proyecto. Aunque estas normas son conocidas y aceptadas, los autores relegan algunas de ellas en sus dibujos, buscando resaltar u ocultar aspectos de sus propuestas. La forma de hacer esto no es ni homogénea ni absoluta, no hay un mecanismo estándar que los arquitectos repitan como un manual. Las decisiones que tomen dependerán del proyecto, las ideas propias del autor y aquello que considere importante para transmitir. Según esto, ¿Qué es lo realmente importante en los dibujos cuando el objetivo no se limita a proyectar un edificio constructivamente, sino a transmitir una idea más amplia?

¿Cuál es la realidad de la arquitectura? ¿Qué son las representaciones arquitectónicas de la realidad? ¿Es absolutamente necesaria su realización (de la arquitectura)?

Lo más importante es la re-presentación de una realidad: Cómo la llamada realidad puede, de hecho, representarse a sí misma en la arquitectura - como, quizás, en una pintura no objetiva de Mondrian. (Hejduk, 1985, p. 312) ${ }^{16}$

\footnotetext{
14 Traducción propia: "When the research succeeds, it can express the ineffable, which is ultimately translated as spirit. Imagine a drawing and a sentence taking shape at the same time."

${ }^{15}$ En algunas ocasiones hace referencia a las estructuras con este término. Aunque inicialmente el objeto puede ser entendido como la estructura y el sujeto como el personaje vinculado a la estructura.

${ }^{16}$ Traducción propia: "What is the reality of architecture? What are architectural representations of reality? Is its (architecture's) realization absolutely necessary?
} 
The re-presentation of an actuality is most important: how the so-called reality can, in fact, represent itself in architecture - as, perhaps, in a non-objective Mondrian painting." 


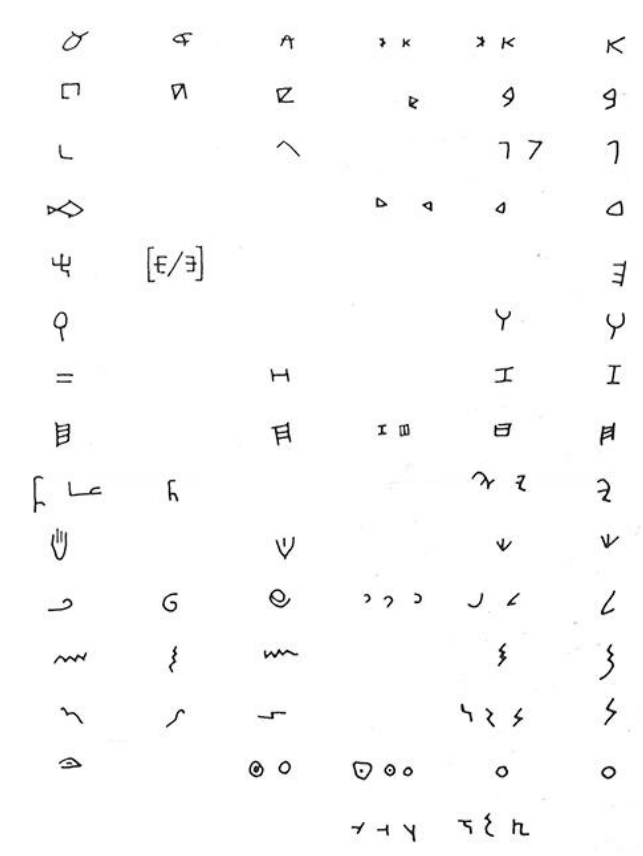

$$
\begin{array}{llllll} 
& A & & p & 9 \\
\sim & \leqslant 3 & w & w & n & w
\end{array}
$$

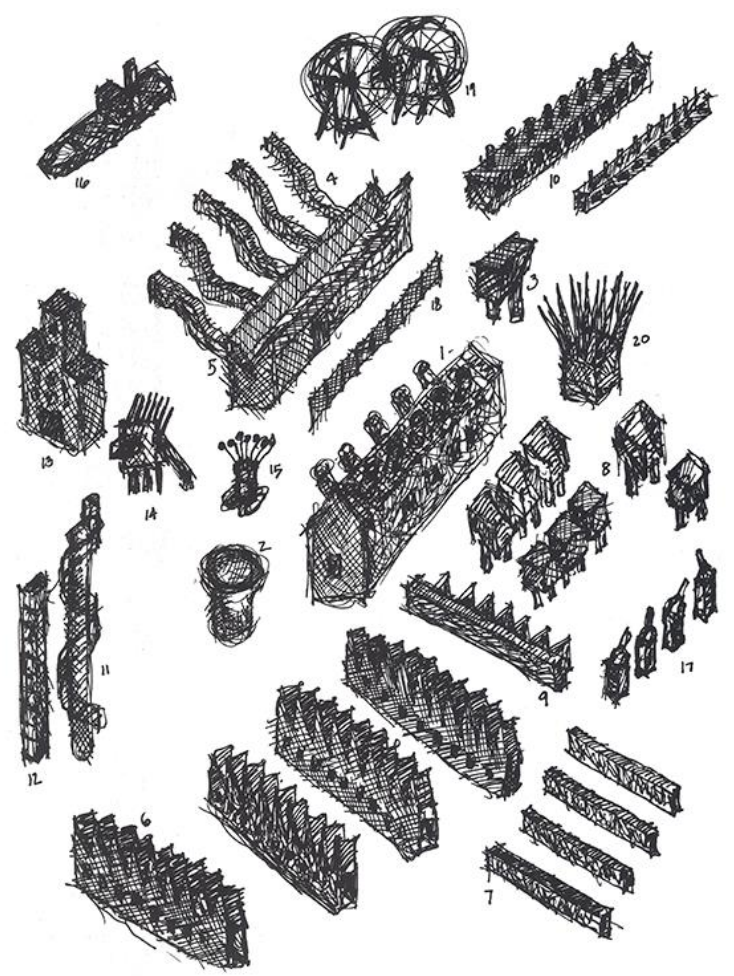

Figura. 5. Arriba: Alfabeto hebreo. Fuente: Hejduk. 1995: 223. Abajo: Sketch de Victims. Fuente: Hejduk, 1986. 


\subsection{La planta}

Victims tiene una única planta, debido a su particularidad y tamaño (mayor en todos los casos) adquiere una importancia relativa a los demás dibujos. Solamente en esta es posible entender las relaciones totales del proyecto, los tamaños de las estructuras y lo que está más allá de los muros circundantes, aunque no de la manzana. Es la única información que hay para comprender el conjunto. Sin embargo, es un dibujo poco ortodoxo. Al verla, la austeridad y economía generan de inmediato una reacción de desconcierto e incertidumbre.

Es un plano sin norte y escala gráfica, sin letras o números, en el cual se sabe vagamente dónde comienza la acera, pero no qué hay más allá, tampoco qué es público y qué es privado, donde no hay topografía ni visualización alguna de la ciudad o sus edificios y calles. La ausencia está presente en el dibujo, lo indeterminado, común en Hejduk, se apodera de esta planta generando una extraña fascinación a quien la observa. Los elementos que la componen quedan sueltos en el plano, son una serie de garabatos y líneas yuxtapuestas que construyen figuras en un fondo que parece flotar detrás de ellas, asemejándose a un cuadro de Paul Klee (Bragdon, 2010, p. 156). Dado que no existe referencia a la ciudad, no es posible saber con seguridad sus dimensiones, podría ser un sitio tanto de carácter barrial como metropolitano.

La línea delimitadora dirige toda la atención del dibujo a lo que esta contiene, sólo lo que pasa al interior es lo relevante. Si hubiera establecido una relación con Berlín (Fig. 7), todo el dibujo tendría una referencia inmediata a la ciudad; por ende, una escala clara. Mostrar las manzanas cercanas, los edificios y las calles, habría conferido un tamaño relativo a las estructuras, facilitando relacionarlas con una función y actividad posible. Ese aislamiento, como explica Lee $(2015$, p. 9), produce nuevos universos y permite que las estructuras pierdan el sentido de escala o referencia.

Sin el contexto, ciertos elementos internos podrían haber denotado la escala del proyecto. Aun así, Hejduk pone puntos mas no siluetas de árboles, no dibuja los adoquines o algún elemento del piso diferente a la línea de la acera, homogeniza gráficamente todos los edificios y reduce el mobiliario al mínimo. Todo esto provoca que la única referencia clara al exterior sean las escaleras de las estructuras y los edificios prexistentes en la manzana ${ }^{17}$. Victims es un mundo en sí mismo.

Ya al interior de los setos, la retícula de árboles actúa como un telón de fondo vivo. Al observar la planta, es clara la preocupación de Hejduk (1993, p. 24) en cuanto a la decisión de eliminar los árboles para construir las estructuras. Los personajes no pueden entrar al escenario sin eliminar un ser vivo, sin crear una huella en el parque. La creación conlleva eliminación. Posarse encima de una existencia previa. Hejduk hace que los berlineses creen nuevas capas de historia, y por tal razón sabe que "Un dialogo sobre este asunto deberá necesariamente tener lugar” (Hejduk, 1993, p. 24).

\footnotetext{
${ }^{17}$ Aunque ambos estén dibujados con gran precisión, la falta de mobiliario dificulta determinar la escala. Hejduk es de los pocos arquitectos que dibujan la distribución arquitectónica de estos edificios.
} 


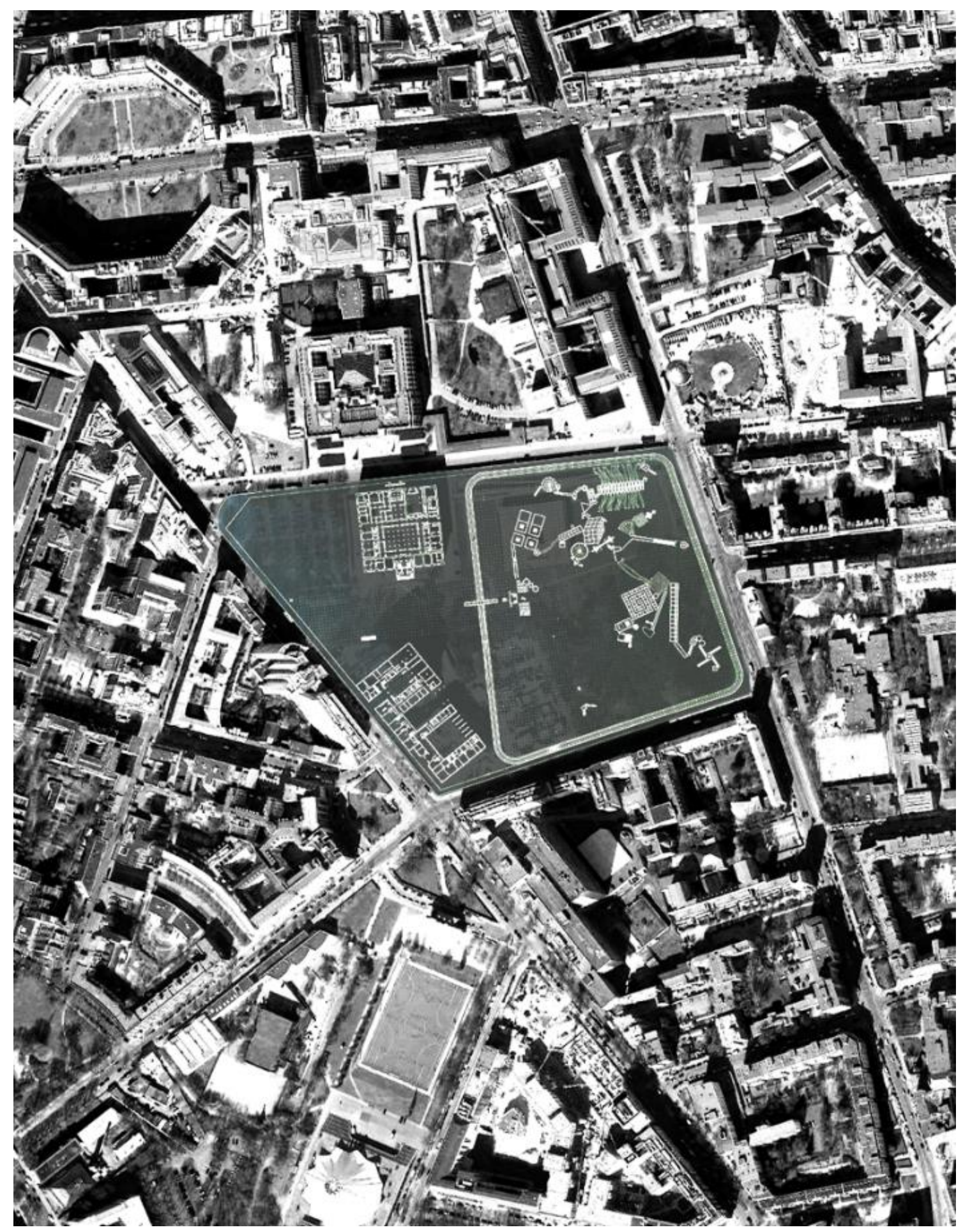

Figura. 6. Victims en Berlín. Fuentes: Elaboración propia.

Torres Nadal, en la presentación de la versión en castellano de Victims (Hejduk, 1993, p. 15), comenta sobre la regla de contacto tangencial entre las estructuras: "Podría haber sido otra, y el resultado podría haber sido cualquier otro." Sin embargo, al entender las estructuras como personajes de la mascarada, es posible notar que la condición de contacto no corresponde a cualquier resultado. Sin esta, los estructuras estarían distribuidas entre los árboles como entes ensimismados. Los personajes aún no están en 
el campo diverso y fluido de la ciudad, como sucederá en Riga (1985) o Vladivostok (1989). Hejduk busca, por lo tanto, la interacción sutil, el encuentro entre los seres que habitan al interior de los setos. Crea una red vagamente articulada (Lee, 2015, p. 8), donde las historias y los espíritus de los personajes pueden entrelazarse.

En la planta, dada sus condiciones, la comprensión de las estructuras es ambigua. Sabiendo que la actividad puede variar entre ellas por su tamaño relativo, podrían funcionar igualmente para una o para varias personas, como juego de niños, oficina de trabajo o zona de exhibición. En este sentido, los dibujos de las estructuras no permiten entender la arquitectura propia de cada una. Están en un punto intermedio, en el cual, si bien pueden ser diferenciadas individualmente, su entendimiento es dado como parte de un conjunto.

Hejduk no incluye el contexto desde la planta de trabajo (Fig. 7). Tiene claro que la narración se encuentra dentro de los muros, en un lugar cuyas historias han sido borradas. Pero ahora hace explicitas las borraduras, ya que en el plano propone una "tabula rasa que oculta con un velo los hechos brutales recientes, como si nada hubiera pasado" (Bascones, 2017, p. 198). A través de la eliminación total del pasado en el dibujo, Hejduk hace que el observador se cuestione: ¿Qué había antes? ¿Por qué está vacío? ¿Cómo pudo proponer algo así? No da respuestas obvias, no resalta las borraduras, las oculta para producir inquietud a partir de su ausencia.

Sobre la tabula rasa aparecen las estructuras. Son ellas las encargadas de evitar que las historias caigan en el olvido. De re-presentarel mundo. De volver a presentar las vidas de aquellos que deben ser puestos en valor. Según Torres Nadal (Hejduk, 1993, p. 11), "no se trata de decretar la desaparición del mundo y de inventarse o de producir otro, sino de representar el nuestro de otro modo y en otro lugar.” Y según Bascones (2017), es la refundación del mundo. En últimos términos, construir una realidad a partir de la consciencia de su propia existencia. Una ciudad dentro de otra. Dos mundos que están siendo contados en paralelo, evitando que Berlín se vuelva Maurilia.

\subsection{Las estructuras / personajes}

“A cada estructura se le ha dado un nombre" (Hejduk, 1993, p. 24), resalta Hejduk en la introducción Victims. Nombrar es re-conocer la existencia, no es un acto pasajero, concede espíritu. Las estructuras dejan de ser solamente objetos/sujetos como categoría, para ser profesionales y sus lugares de trabajo. Adquieren individualidad. Luego de conocer las relaciones generales, es necesario adentrarse en los personajes de la mascarada, un acercamiento al ser. Comprender los protagonistas para entender las historias que pueden narrar. 


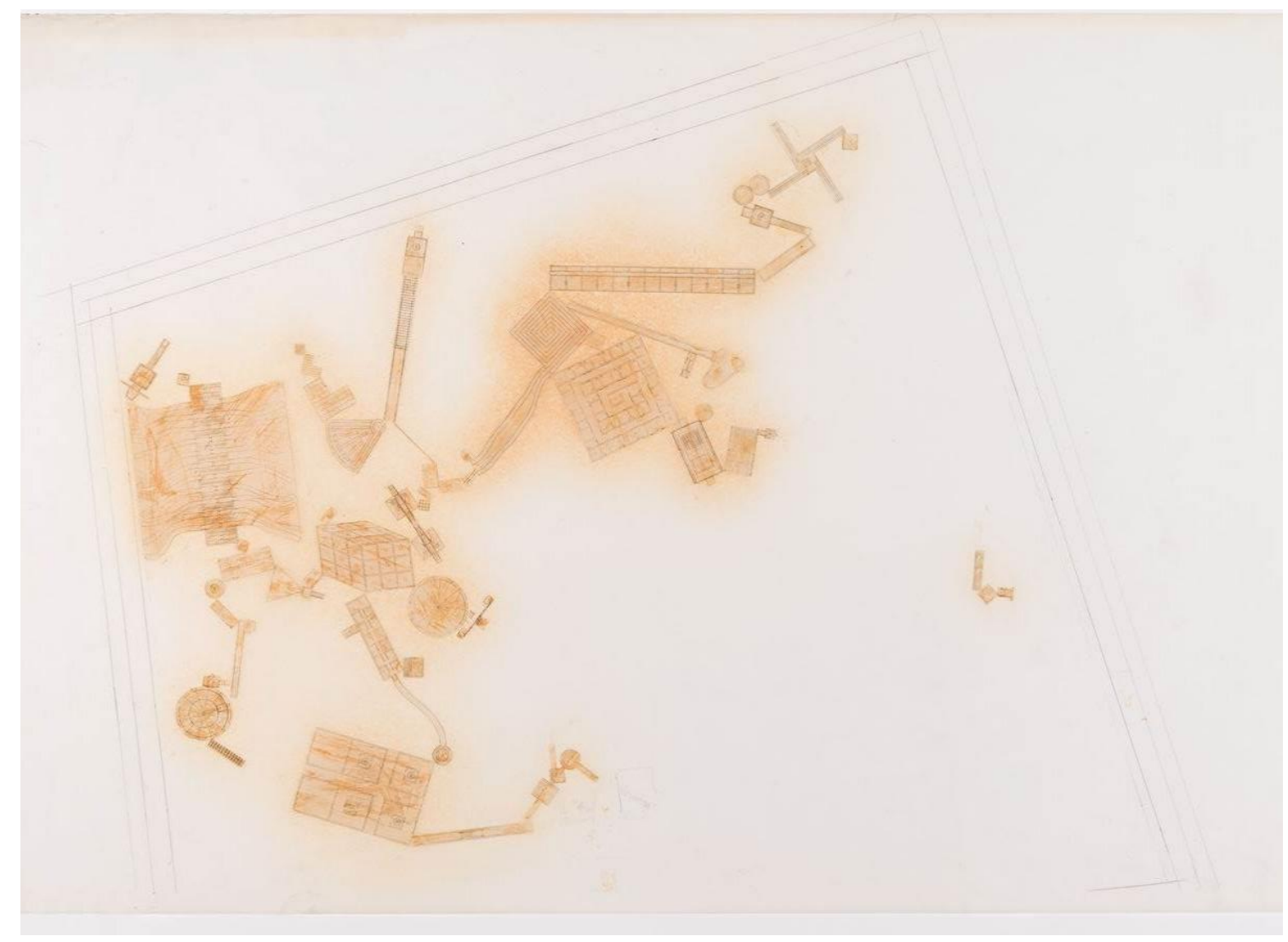

Figura. 7. Parte de la planta de trabajo para Victims I. Montreal: John Hejduk Fonds, CCA. [Consulta: 27 de abril de 2021] Disponible en: https://www.cca.qc.ca/en/search/details/collection/object/367457.

Durante más de 15 años, Hejduk fue creando un vasto repertorio de personajes, aproximadamente 400. Esta troupe, como él los llamaba, fue creciendo con cada nuevo proyecto, con cada nuevo edificio. En la entrevista que le hizo Shapiro (2010, p. 80), Hejduk afirma que le es imposible pensar un edificio sin construir nuevos personajes e historias. Nuevas emociones, recuerdos, percepciones y aspiraciones. Al momento de hacer un edificio debe crear nuevas letras que le permitan nutrir su lenguaje y "construir nuevos mundos" (Shapiro, 2010, p. 80).

En Victims coexisten 67 estructuras. Personajes que han sido ideados desde la cotidianeidad con nombres, oficios y recuerdos. Hejduk se aleja de las historias grandilocuentes de los que normalmente son considerados los actores únicos de la sociedad. Re-presenta a aquellos que muy rara vez fueron presentados en los relatos de la memoria, esos por los que tanto pregunta Bertolt Brecht ${ }^{18}$.

Los ha construido sistemáticamente con los mismos elementos. Una forma de pensar traducida a dibujos y palabras. Torres Nadal (Hejduk, 1993, p. 11) considera a la sistematicidad como el factor "que le otorga a cada nombre la condición de completo: un número, un orden, un nombre, una correspondencia sujeto-objeto y un recorrido." Solo basta ver el libro para entender el patrón. Primero: numeración y nombramiento de los personajes y sus complementos espaciales. Segundo: narraciones de cada uno de los

${ }^{18}$ Ver "Preguntas de un obrero que lee". Bertolt Brecht. 
personajes previamente nombrados y enlistados. Tercero: los dibujos, las formas de los personajes.

Por medio de breves textos, poemas, descripciones o definiciones, Hejduk logra compartir las emociones, sensaciones, recuerdos, añoranzas y creencias de sus personajes (Fig. 9. Arriba). No son grandes despliegues de sus vidas, ni fichas técnicas sobre los aspectos de su ser. Mas bien, son esbozos que permiten comprender un poco la realidad de cada ser, una visión parcial, un fragmento de sus memorias. Uno tras otro, los relatos abren los universos particulares de la troupe que participa en la mascarada, compartiendo al lector lo justo para crear curiosidad, para que este pueda completar la historia, el espíritu, de los personajes con sus propias memorias.

Para Torres Nadal (Hejduk, 1993, p. 13), solo el dibujo puede contestar a la duda “¿Qué es una forma cuando el contenido no se puede pensar porque ese contenido es ya solo memoria?". Los dibujos tienen la responsabilidad de materializar el espíritu de aquellos que han sido olvidados. De "expresar lo inefable" del ser (Hejduk, citado en CCA, 1997).

Los dibujos aparecen de dos formas: los bocetos hechos a mano alzada por Hejduk (Fig. 8. Abajo der.) y las proyecciones ortográficas hechas por Boyarsky (Fig. 8. Abajo izq.). Los primeros poseen más expresividad, más cercanos a un símbolo o ícono. Generalmente están puestos uno al lado del otro y numerados, es poco común que haya más de una vista (Fig. 4 ,5 y 9). Los segundos son más cercanos al dibujo arquitectónico tradicional, normalmente aparecen dos proyecciones: la planta y un alzado o corte (Fig. 8. Abajo izq.). No obstante, al igual que sucede en la planta, no tienen cotas, relación alguna con el exterior, ni con las otras estructuras. Adicionalmente no comparten la misma escala, lo cual da como resultado que solo sea posible conocer la dimensión real de las estructuras al observar la planta general. Ambos tipos de trazo tienen en común la condición de presentar personajes aislados, seres que en la mayoría de los casos están uno al lado del otro sin interactuar.

Las palabras y los dibujos se complementan para formar los personajes, pero Hejduk niega su lectura directa y continua. Cada una de las partes es independiente, posee un espacio propio dentro de la publicación y, como es evidente, una forma propia de ser puestas sobre el papel (Fig. 8). Obliga al observador a desplazarse en el libro, pasar continuamente de la imagen al texto, del ícono al contenido. Hace que la mente siempre esté participando de la creación y materialización de los personajes. "Sin título o rótulos, el lector debe vincular el ícono con el texto enlistado. En este acto, el icono/emblema se vuelve más que un dibujo" (Bragdon, 2010, p. 159) ${ }^{19}$. El observador debe participar en la elaboración del relato, su imaginación se activa cuando une los fragmentos de memoria y el contendor en un ser único. ${ }^{19}$ Traducción propia: "Without title or labels, the reader must match icon with listed text. In the effort, the
icon/emblem becomes more than a drawing." 
23 Musician

The Musician is given Studio B in the park in order to compose.

\section{Dutch Interior}

The mandolin intestines of bollowed black crystals slide against the internal curvature ultimately released through the bole of stretched fibers held

then diminished in a tap
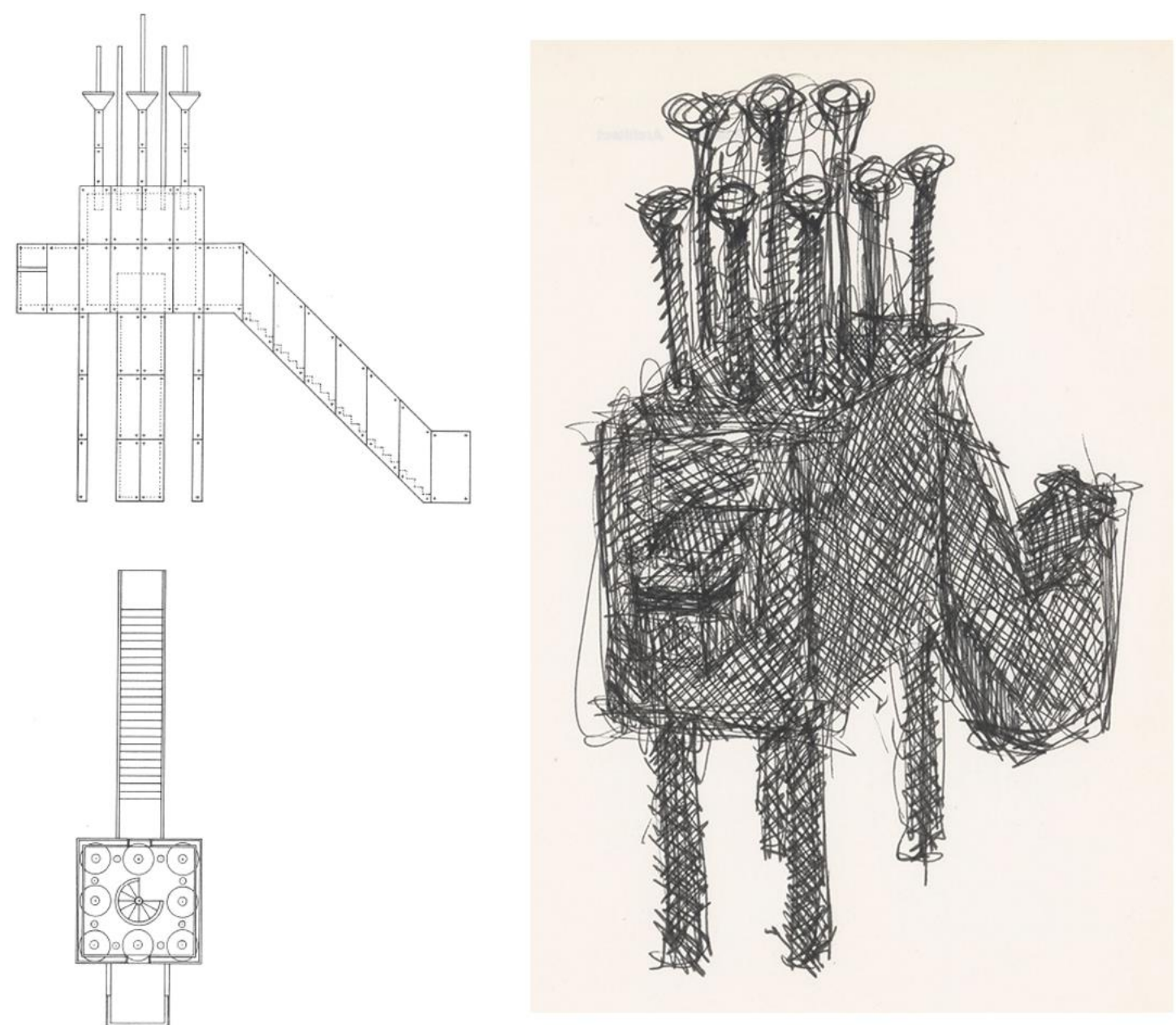

Figura. 8. El músico - Estudio B. Arriba: Narración. Abajo izquierda: Dibujo, elaborado por Boyarsky. Fuente: Hejduk, 1986. Abajo derecha: Boceto, elaborado por John Hejduk. Fuente: John Hejduk Fonds, CCA. [Consulta: 27 de abril de 2021] Disponible en: https://www.cca.qc.ca/en/search/details/collection/object/491158 


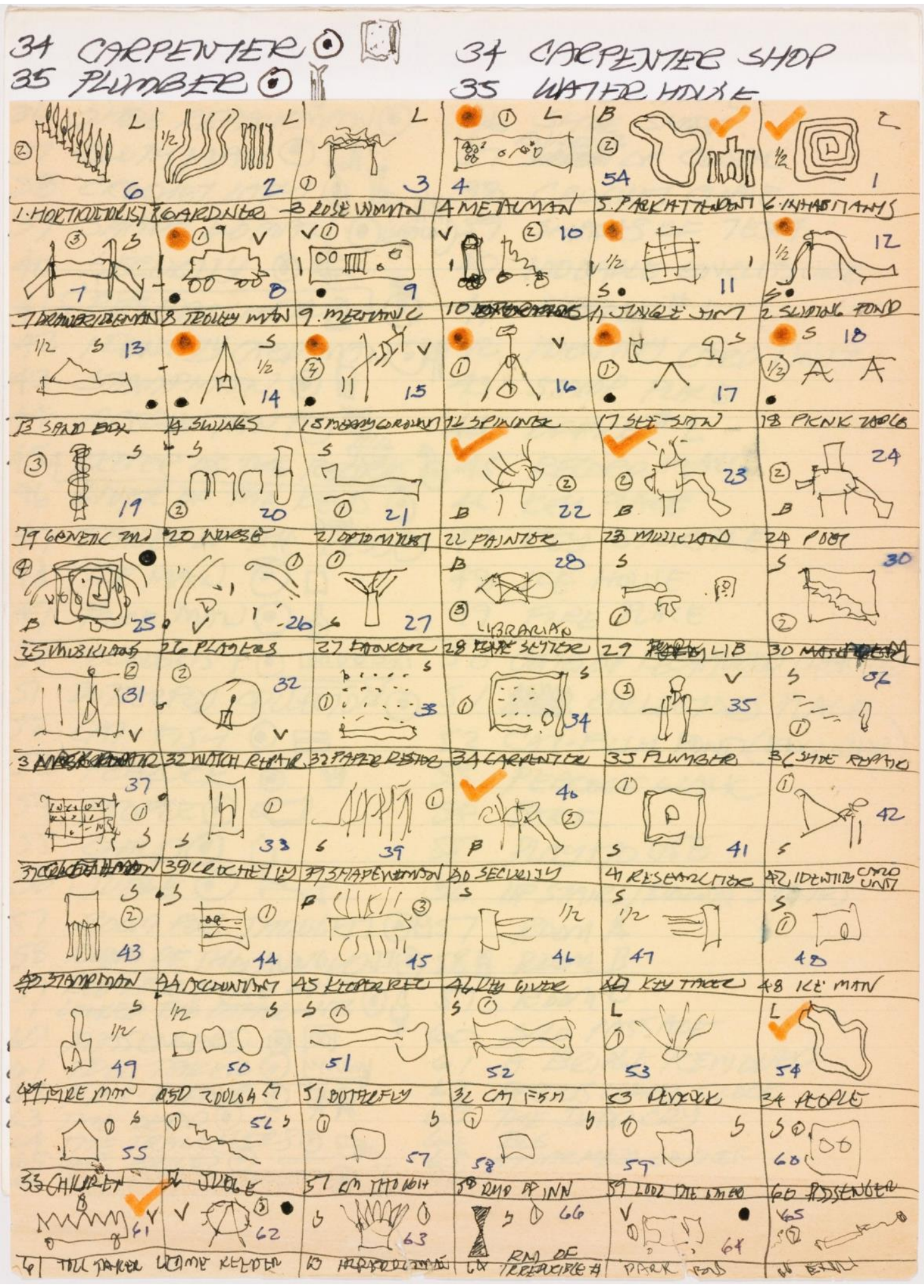

Figura. 9. Tabla y lista de los personajes de Victims. John Hejduk. Fuente: John Hejduk Fonds, CC. [Consulta: 27 de abril de 2021] Disponible en: https://www.cca.qc.ca/en/search/details/collection/object/455688 
Hejduk presenta un catálogo a la ciudadanía de Berlín. El uso de la palabra catálogo establece una relación particular con las estructuras. Catalogarlas denota un conocimiento, análisis e interpretación previo, a la vez que, al ponerlas como opciones, las iguala en tanto personajes que se pueden elegir de una lista para conformar la obra. Diferente a las famosas catalogaciones de Durand, en donde los elementos no son una totalidad sino los partes que permiten componer la obra, la estructuras en Victims son obras completas en sí mismas, estructuras de las que se dispone para generar una unidad basada en la interrelación de entidades autónomas. La técnica de collage, utilizada en la planta de trabajo (Fig. 7), denota el mismo carácter de autonomía previa al emplazamiento y visualiza el mecanismo de relación entre entidades independientes en un área vacía, solamente delimitada por las líneas que reflejan los muros.

Varios de los bocetos muestran la condición de catálogo (Fig. 9). Son dibujos aislados, en algunos casos siguiendo un patrón claro de cuadricula y en otros solo dispuestos sobre el papel (Fig. 4). Están listos para ser seleccionados a voluntad según la historia que quiera ser contada. A semejanza de los créditos iniciales de una película, la lista del principio del libro indica los personajes que participaran en la obra.

Como un gran guionista, Hejduk crea sus personajes observando detalladamente la realidad, no para copiar exactamente lo que ve, sino para presentar otra versión de esta. Entiende a través de sus discusiones internas que no es posible copiar la vida, el espíritu de una persona. En las Notas para la construcción de un Diario (Hejduk, 1993, p. 86), escribe el 28 de septiembre: “Calcar la vida de otro." Dos días después, el 30 de septiembre, reconoce: "Es imposible calcar la línea de otro, el pensamiento desaparece".

Bragdon (2010, p. 19) entiende a las mascaradas como construcciones íntimamente ligadas al lugar donde se emplazan, ya que este les confiere condiciones primordiales para su creación. Por consiguiente, considera errada la idea de Moneo (citado en Bragdon, 2010, p. 20) de "un tipo Hejdukiano donde un universo contenido de figuras arquitectónicas asume y ocupa un espacio genérico" ${ }^{20}$. Si bien las dos visiones parecen contrarias, puede existir una conciliación. Hejduk crea un lenguaje propio que compila en su troupe de personajes, cada uno con recuerdos y emociones particulares, a esto se refería Moneo con el "universo contenido", no solo está contenido físicamente, sino en los términos que ha creado Hejduk; sin embargo, contrario a estar ubicadas en un "espacio genérico", los sitios seleccionados están cargados de significados y capas históricas que siempre influyen en los personajes de las mascaradas. El ejemplo más claro de esta relación, como cita Bragdon (2010, p. 21), es el Filatelista ${ }^{21}$.

Hejduk es un director que escoge y conoce sus escenarios, no pueden ser espacios genéricos, él sabe el peso histórico y narrativo que tienen. Por lo tanto, selecciona adecuadamente a sus personajes, toma los que consideran relevantes, crea nuevos y

\footnotetext{
${ }^{20}$ Traducción propia: "Hejdukian one in which a contained universe of architectural figures assumes and occupies a generic space."

${ }^{21}$ La historia del filatelista hacer referencia directa al periodo del régimen nazi. “Quita los sellos de los sobres de las cartas no contestadas. Actúa como depositario de los sobre que datan aproximadamente de 1931 a 1946..." (Hejduk, 1993, p. 51).
} 
adiciona capas a los antiguos, para así, completar el elenco de las nuevas mascaradas. La troupe viene de antes y se va agrandando con cada proyecto nuevo, aunque hay "actores recurrentes" e historias similares, los personajes que ha seleccionado interactúan activamente con el lugar.

En este proyecto, los sujetos modifican el entendimiento de las víctimas de la Segunda Guerra Mundial. Evidencian que son un grupo heterogéneo, con diversas aspiraciones y visiones, los saca de una generalización, les confiere un nombre. Hejduk le da la opción a la ciudadanía de reconocer sus víctimas. Ellos, los Berlineses, son los que deciden cuales y de qué manera las van a recordar. No es una imposición del autor, sino la decisión colectiva de re-presentar o no su memoria. Esto implica afrontar los hechos del pasado para así utilizarlos en la construcción del futuro. El valor de las mascaradas sobrepasa el carácter del dibujo o el texto, como expone Bragdon (2010, p. 22) ${ }^{22}$ :

Las mascaradas son más que el texto o el dibujo; como su inspiración, la Stuart Court Masque, esta forma de arquitectura es un compendio de texto, símbolo, historia, y performance, cuyo objetivo es dirigir al observador y al participante a una comprensión mas amplia del rol del ciudadano en la creación de comunidad.

Nombrar los entes del catálogo es difícil. Sujetos/objetos, personajes/estructuras, profesión/lugar de trabajo, alma/cuerpo; todos son válidos. Hejduk ha adicionado tantas capas, componentes y características que no es posible llamarlos solamente estructuras o personajes. Torres Nadal (Hejduk, 1993, p. 14) los llego a llamar juguetes. Dotarlos de una categoría propia sería tentador, pero, tener tal contundencia para definirlos seria encasillarlos y cerrar, en gran medida, las puertas de la interpretación.

\section{Lo no revelado del dibujo}

Las mascaradas no son obras teatrales cuyo desarrollo se da por una historia única y direccional, con actos claramente divididos. Son, por el contrario, obras que "generalmente adolecen de inicio, nudo o desenlace" (Hejduk, 1985, p. 137) ${ }^{23}$. Hejduk, siguiendo esta idea, presenta su mascarada de tal forma que no haya una acción detonante ni un guion definido, sino un esquema general al cual los personajes presentados deben ceñirse. Por medio de relaciones sencillas, provoca una interacción libre entre los individuos, diversifica las historias y posibilita la creación de nuevas realidades. Es la vida de una ciudad tomando forma. La vida de las víctimas presentándose a los berlineses, los cuales "son invitados a este juego que inicia la troupe de Hejduk, sin saber que no es un juego inocente, que, una vez seducidos, les va a enfrentar con su pasado más oscuro" (Bascones, 2017, p. 231).

Hejduk, en The Flatness of Depth (1985, p. 312-313), declara: “Debe ser entendido que la llamada arquitectura total es, en última instancia, hecha de partes y fragmentos, $\mathrm{y}$

${ }^{22}$ Traducción propia: "The masques are more than the text or the drawing; like their inspiration, the Stuart Court Masque, this form of architecture is a compendium of text, symbol, history, and performance, which is meant to lead the viewer and the participant to a greater comprehension of the citizen's role in the creation of community."

${ }^{23}$ Traducción propia: "Originating in England where they were first called "Mummery", generally lacked story action, crisis or ending." 
fabricación"24. Al ver su trabajo, esta posición frente al entendimiento de la arquitectura es fácilmente reconocible. Sus libros son presentados a través de fragmentos, de secciones que muestran diferentes facetas de la obra. En las publicaciones existe una constante separación entre ellos: textos, pensamientos, numeraciones, dibujos, poemas y bocetos suelen ir por separado, en páginas aparte o capítulos distintos, son visiones separadas de la misma obra. Si bien, cada una de estas partes es independiente a tal grado que podría funcionar por sí sola, el entendimiento global se da al vincularlas, al ir de una a la otra enlazando los significados particulares en una narración coherente. Por este mismo motivo, el orden de lectura es una sugerencia. No hay una forma única de leer el contenido. Un observador puede comenzar por las directrices iniciales, otro por los dibujos y un tercero por las narraciones, al final, todos deberán ir a las demás partes en busca de clarificar la totalidad.

El observador adquiere un papel activo en la obra ya que es él quien debe unir las partes de esta en su mente. Los dibujos y los textos lo incitan a involucrarse con el contenido y a desarrollar las conexiones por sí mismo. Hejduk da el mensaje inicial, lo justo para que la mente-alma del observador empiece a volar, yendo de un fragmento al otro, uniendo los hilos expuestos, para así poder tejer una historia personal. Como expresa Van Den Bergh en el texto Seven Memos on the Geometry of Pain, parte de Soundings (Hejduk, 1993, p. 23): "El lector está necesariamente involucrado en el texto, de tal manera que lo activa. El lector tiene que animar el cuerpo del texto, realmente debe tejerlo o desarrollarlo, y debe estar inmerso en este libro" ${ }^{25}$. De esta forma, los fragmentos propuestos por Hejduk se unen con los fragmentos de memoria del observador para construir una realidad singular, una versión única de la mascarada. Hejduk sabe que podrá haber tantas versiones de Victims como espectadores tenga la obra. Su intención no es monopolizar la verdad, ni crear una historia oficial, sino evidenciar que la memoria es diversa y está llena de matices.

"La arquitectura es la única forma de arte que nos permite ser voyeurs que miran el exterior desde afuera y, a la vez, ser observadores internos" (Hejduk, 1985, p. 313) ${ }^{26}$. En la obra de Hejduk, los espectadores están moviéndose constantemente entre el exterior y el interior de los personajes/estructuras que conforman la mascarada, entre la escena general y el desarrollo particular. A través de sus mentes van de un de un fragmento al otro; pasan de la planta, a los dibujos y luego a los a textos, todo para volver nuevamente a la planta. No hay un orden específico, la deriva es personal. Los pensamientos propios de quien observa deben gravitar por las partes del proyecto, cambiar entre diversas escalas y profundidades, relacionar dibujo con texto, materia con espíritu.

\footnotetext{
${ }^{24}$ Traducción propia: "It must be understood that so-called total architecture is ultimately made up of parts and fragments and fabrication."

${ }^{25}$ Traducción propia: "The reader is necessarily involved in the text in such a way as to activate it. The reader has to animate the body of the text, must actually weave or de-velop it, and must be in-volved in this book."

${ }^{26}$ Traducción propia: "Architecture is the only art form that affords us the opportunity of being voyeurs who watch the outside from the outside and also of being interior watchers."
} 
Hejduk separa las partes que construyen conjuntamente a los personajes, de esta forma, guía al observador a vincular ícono y significado. Entrar al interior del ser, comprender su historia, emocionarse, sentir... salir y ver el dibujo, divisar el impacto de la forma, construir el individuo, unir contenido y contenedor, percibir el espíritu. Por medio del esfuerzo mental, de participar activamente en la obra, el observador logra presenciar lo inefable, aquello que hace trascendental a las letras de Hejduk. Esta búsqueda continuará en los siguientes proyectos, en la ampliación constante de los personajes que conformarán su gran repertorio, pero, al mismo tiempo, creará una vertiente fascinante de su trabajo: atrapar ángeles. ¿Cómo re-presentar el espíritu? Tal vez los seres alados son la respuesta.

A partir de imágenes fijas, Victims parece constituir la síntesis máxima de una obra teatral. Una sucesión de cuadros con los personajes, las anotaciones del director y una única escena, donde las circunstancias establecidas son mínimas y, por lo tanto, la realidad puede ser re-presentada de múltiples formas. En este sentido, la planta es la imagen del instante de vida en comunidad, llena de relaciones e historias conjuntas que aún están por ser clarificadas o creadas; los personajes, por otro lado, son todas las posibilidades de desarrollo de las escenas, cada vida propone situaciones e interacciones diferentes. Es así como el movimiento espiritual del observador se origina del reposo, de confrontar detalladamente las imágenes y "agudizar la mente al extremo, exorcizando de una imagen fija, toda sus posibles sensaciones y significados” (Hejduk, 1985, p. 313) ${ }^{27}$.

La forma de actuar de Hejduk está más dirigida a encontrar lo fundamental que a ocultar. Sabe lo que está presentando en cada fragmento de la obra y entiende que hay elementos de los cuales puede prescindir en sus elaboraciones. Los dibujos, los pensamientos, las anécdotas y las narraciones están reducidas a su mínima expresión, tamizadas hasta encontrar aquello que las hace únicas. Poner más sería innecesario y eliminaría la emoción de encarar la obra ¿Cuál es el sentido del arte sino inquietar? Busca re-presentar lo necesario para que la esencia pueda ser transmitida, para que la mente del observador vincule lo que tiene frente a sus ojos con su memoria $\mathrm{y}$, de manera pausada $\mathrm{y}$ confrontativa, revele sus misterios.

\section{Referencias}
AA ARCHIVES
CATALOGUE.
John
Hejduk,
1986.
(n.d.)
http://archives.aaschool.ac.uk/Record.aspx?src=CalmView.Catalog\&id=AA\%2f02\%2f01\%2f03\%2f
28 [Consulta: 27 abril 2021]

BASCONES DE LA CRUZ, G. Francesco Venecia y John Hejduk: la vigencia del arte de la memoria en la arquitectura contemporánea [en línea]. Tesis Doctoral Inédita. Universidad de Sevilla, 2017. pp. 171-384. http://hdl.handle.net/11441/64980 [Consulta: 29 abril 2021]

BRAGDON, A. Drawing, Writing, Embodying: John Hejduk's Masques of Architecture [en línea]. Tesis doctoral. Virginia Polytechnic Institute and State University, 2010, pp. 145-

\footnotetext{
${ }^{27}$ Traducción propia: "The mind of the observer us heightened to an extreme, exorcising out from a single fixed photographic image all its possible sensations and meanings."
} 
220.https://vtechworks.lib.vt.edu/bitstream/handle/10919/29724/Gilley_AB_D_2010.pdf?sequen ce=2\&isAllowed=y [Consulta: 28 abril 2021]

CCA, CANADIAN CENTRE FOR ARCHITECTURE. Other Soundings: Selected Works by John Hejduk, 1954-1997. Montreal, 1997. https://www.cca.qc.ca/cca.media/files/9033/7979/hejduk_pressrelease.pdf [Consulta: 27 abril 2021]

CALVINO, I. Las ciudades invisibles. Traducido por BENEDETTI, A. Buenos Aires: Crisálida Crasis, 2008, pp. 39-40.

EVANS, R. Translation from Drawing to Building and Other Essays. Londres: Architectural Association, 1997, pp. 152-193.

GERSTEN, D. 04.18.17 / Prof. David Gersten: Two Talks on John Hejduk, Part 1 / Hejduk, Hamlet and the Ghost... Youtube, 2019. https://www.youtube.com/watch?v=UH7zy3MpOH0 [Consulta: 28 abril 2021]

HAYS, K. "Of Mirrors and Ashes and Beginning Again: A Note on Hejduk's Instauration of Brunelleschi's Experiment”. Harvard Design Magazine: Do You Read Me? [en línea] no. 38, 2014, pp. 56-61. https://static1.squarespace.com/static/58234e7f9de4bb39337cc292/t/584e1a2dbebafb9fcae99e89 /1481513518099/HDM38_Hays.pdf [Consulta: 27 abril 2021]

HEJDUK, J. Victimas. Traducido por MORENILLA, M. y SÁNCHEZ, T. Murcia: Colegio Oficial de Aparejadores y Arquitectos Técnicos, 1993, pp. 9-15.

HEJDUK, J. Soundings. Nueva York: Rizzoli International Publications, Inc. 1993.

HEJDUK, J. Bovisa. Nueva York: Rizzoli International Publications, Inc. 1987.

HEJDUK, J. Victims. Londres: Architectural Association. 1986.

HEJDUK, J. Mask of Medusa: Works 1947-1983. Ed. por SHKAPICH, K. New York: Rizzoli International Publications, Inc, 1985.

IBA, INTERNATIONALE BAUAUSSTELLUNG. "Dokumentation. Offener Wettbewerb Berlin, Südliche Friedrichstadt: Gestaltung des Geländes des ehemaligen Prinz-Albrecht-Palais". Berlin: Internationale Bauausstellung, 1987, pp. 4-121.

LEE, M. (2016) "Two Deserted Islands". JOHNSTON, S. y LEE, M. The Architectural Double in the Museum City [en línea]. Cambridge: Harvard University Graduate School of Design, 2016, pp. 134139. https://issuu.com/gsdharvard/docs/thearchitecturaldouble> [Consulta: 29 abril 2021]. ISBN 978-I-934510-56-8

SHAPIRO, D. “El Arquitecto que Dibujaba Ángeles: Entrevista con John Hejduk. Traducido por MAIRA, A. Minerva: Revista Del Círculo De Bellas Artes [en línea] no. 14, 2010, pp. 78-82. https://cbamadrid.es/revistaminerva/articulo.php?id=413 [Consulta: 29 abril 2021]

\section{Bio}

Arquitecto. Universidad Nacional de Colombia. 2019. Miembro del Equipo Víctimas. 